Portland State University

PDXScholar

Summer 2021

\title{
Beaver Reintroduction and Its Potential as an Ecological Conservation Measure for At-Risk Amphibian Species in the Pacific Northwest
}

Danielle Schwantes

Follow this and additional works at: https://pdxscholar.library.pdx.edu/honorstheses

Part of the Forest Biology Commons, Forest Management Commons, and the Terrestrial and Aquatic Ecology Commons

Let us know how access to this document benefits you.

\section{Recommended Citation}

Schwantes, Danielle, "Beaver Reintroduction and Its Potential as an Ecological Conservation Measure for At-Risk Amphibian Species in the Pacific Northwest" (2021). University Honors Theses. Paper 1127. https://doi.org/10.15760/honors.1158

This Thesis is brought to you for free and open access. It has been accepted for inclusion in University Honors Theses by an authorized administrator of PDXScholar. Please contact us if we can make this document more accessible: pdxscholar@pdx.edu. 


\title{
Beaver reintroduction and its potential as an ecological conservation measure for at-risk amphibian species in the Pacific Northwest
}

\author{
by \\ Danielle Schwantes \\ An undergraduate honors thesis submitted in partial fulfillment of the \\ requirements for the degree of \\ Bachelor of Science \\ in \\ University Honors \\ and \\ Environmental Science and Management
}

Thesis Advisor

Dr. Jeffrey Gerwing

Portland State University 


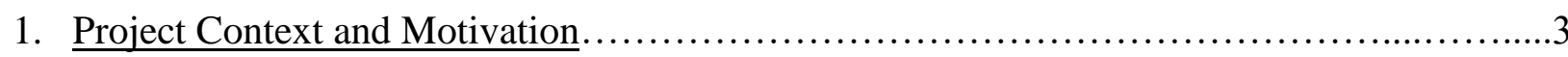

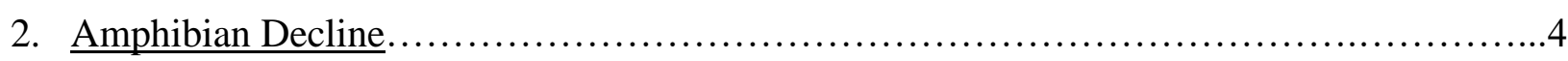

a. Decline in the Pacific Northwest...............................................4

b. Relationship to Riparian Zones and Wetlands and Potential Impacts of Habitat

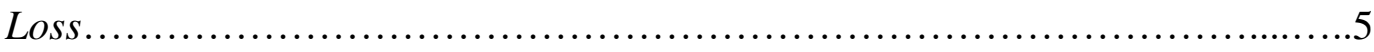

c. Potential Impacts of Climate Change ..........................................5

d. Ecological Consequences of the Loss of Amphibians.............................6

3. Beaver Conservation and Management in the Pacific Northwest.............................6

a. Strategies and Findings of Beaver Reintroduction.............................6

4. Ecological Effects of Beavers on Wetlands................................................

a. Hydrology and Geomorphology .............................................

b. Landscape Heterogeneity ..................................................

c. Biodiversity ............................................................ 8

5. Ecological Effects of Beavers on Amphibians .........................................

a. Amphibian Habitability .....................................................10

b. Amphibian Breeding........................................................11

c. Population Connectivity ...................................................12

d. Climate Change Resilience ...................................................12

6. Beavers as an Ecological Management Option in the Pacific Northwest.......................13

a. Conservation of PNW Amphibians............................................14

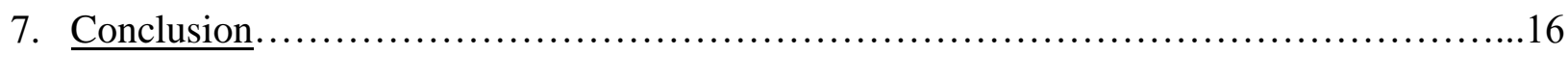

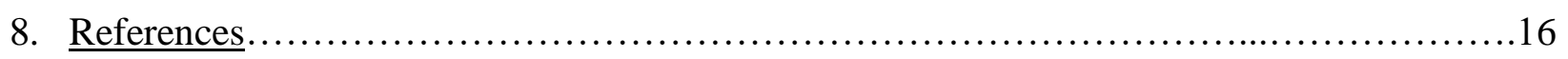




\section{$\underline{\text { Project Context and Motivation }}$}

Amphibian populations are in severe decline in the Pacific Northwest (PNW) (Hossack et al, 2015; Walls et al, 1992; AmphibiaWeb, 2021). The PNW includes the range of the Oregon Spotted frog (Rana pretiosa), listed as threatened by the Endangered Species Act (ESA). There are many other at-risk amphibian species listed as sensitive, threatened, or endangered throughout the PNW. In this region, several species of amphibian have become locally extinct, while the ranges of numerous species have become drastically reduced (Walls et al, 1992). Many researchers predict the cause of the decline to be loss of their wetland habitats due to climate change and anthropogenic stressors (Hossack et al, 2015; Remm et al, 2018; Popescu \& Gibbs, 2009; Karraker \& Gibbs, 2009). Wetlands are disappearing, with approximately $50 \%$ of the world's wetlands lost or degraded (Karraker \& Gibbs, 2009; Remm et al, 2018).

The reintroduction and population management of beavers into ecoregions of the Pacific Northwest could be an important step in the conservation of this region's wetlands and amphibians. Beavers are ecosystem engineers and, through structural manipulations of forest ecosystems, are able to create larger wetlands that are highly preferred by amphibians (Hood et al, 2008; Pollock et al, 2009; Karracker et al, 2009). They are able to restore wetland quality, productivity and biodiversity and their ponds provide excellent breeding habitats and increase the survivability of amphibians at all life stages (Law et al, 2019; Karracker et al, 2019). As the creators of vital amphibian habitat, beavers could put ecosystems back into balance by performing important wetland and aquatic ecosystem processes. Their reintroduction into ecoregions where amphibians are at-risk could be a key to mitigating the decline of PNW amphibian populations.

Beaver presence is a biophysical variable that can be linked with amphibian species richness, occupancy, and community dynamics, however this is still an emerging area of research (Hossack et al, 2015). This work explored the linkage between beaver presence and wetland hydrology, geomorphology, landscape heterogeneity, and biodiversity, as well as amphibian habitability, breeding, population connectivity, and climate change resilience to gain a greater understanding of how beavers could be a tool for habitat restoration and species conservation via reintroduction. The goal of this project was to determine if the reintroduction of beavers is a viable tool for the stabilization and support of at-risk amphibians (listed as either candidate, sensitive, special concern, threatened, or endangered) in the Pacific Northwest, using case studies that focus on amphibian species special needs, limiting factors, and recommended conservation actions. Specific emphasis was placed on reintroducing beavers as a tool for habitat restoration, ecological management, and amphibian conservation. This study focused on anuran amphibians, 
as this order of amphibians is more likely to be influenced by beaver ecosystem engineering and would more greatly benefit from the environmental changes caused by beavers after successful reintroduction.

\section{$\underline{\text { Amphibian Decline }}$}

Amphibians (class amphibia, containing over 8,000 species) are vertebrates with unique life histories and physical characteristics (AmphibiaWeb, 2021). Due to their unique adaptations, amphibians are extremely sensitive to changes to their environment including disease, pollution, toxic chemicals, ultraviolet radiation, and habitat destruction (USGS). Amphibian populations around the world have experienced significant declines within the last couple of decades, exceeding those seen in any other vertebrate class (Hossack et al, 2015). More than $30 \%$ of the world's amphibians are threatened and 43\% have populations that are declining, with 168 species believed to have gone extinct (AmphibiaWeb, 2021; Carvalho et al, 2020). The specific cause for the declines is unknown, making conservation efforts difficult. Although there is a long history of amphibian declines, long-term trends are lacking, and many ecological factors associated are not well understood; however, many researchers predict that the major causes are loss of habitat and climate change (Hossack et al, 2015; Remm et al, 2018; Popescu \& Gibbs, 2009; Karraker \& Gibbs, 2009).

\section{Decline in the Pacific Northwest}

The Pacific Northwest is made up of the states of Oregon and Washington, as well as regions of Idaho, California, and the Canadian province of British Columbia. Despite the PNW containing $17 \%$ of all amphibian species found in the U.S. and $49 \%$ of all species found in Canada, amphibian decline is particularly severe in this region, with a long history of declines being documented (Hossack et al, 2015; Walls et al, 1992).

The Oregon Spotted frog is an amphibian of the Pacific Northwest region with a range that falls within the United States; it is currently listed as threatened under the United States ESA. Four other amphibians of the PNW have been candidates for listing under the ESA in the past including the Northern Red-Legged frog ( $R$. aurora), Cascades frog ( $R$. cascadae), Larch Mountain salamander (Plethodon larselli), and Siskiyou Mountains salamander (P. stormi) (Walls et al, 1992). In British Columbia, there are 11 amphibian species listed as endangered, threatened, or of special concern under the Species at Risk Act (SARA) (WildResearch, 2015). In Washington, there are 9 species listed as candidate, sensitive, or endangered (WDFW). In Oregon, there are 17 species that are classified as strategy species, or species of concern by the Oregon Conservation Strategy (Oregon Conservation Strategy). These 17 species are also listed 
as sensitive by the Oregon Department of Fish and Wildlife (ODFW). In Idaho and California, there are 4 amphibian species listed on these state's sensitive and candidate lists with regions that fall within the PNW, including the Columbia Spotted frog (R. luteiventris) (Idaho) as well as the Cascades frog, the Foothill Yellow-legged frog ( $R$. boylii) and the Oregon Spotted frog (California Natural Resources Agency, 2021; Idaho Governor's Office of Species Conservation). In the Pacific Northwest, populations of several species of amphibian have already become locally extinct, while the ranges of numerous species have become drastically reduced (Walls et al, 1992).

\section{Relationship to Riparian Zones and Wetlands and Potential Impacts of Habitat Loss}

The main habitat of amphibians is wetlands or riparian zones. Wetlands are unique habitats, extending from the edge of a water body to above the high-water mark. They are influenced by the water table, which is in turn influenced by streams, rivers, tributaries, hillslope runoff, precipitation and alluvial aquifers (Westbrook et al., 2006). They are vital ecosystems, providing important ecosystem services and habitat to amphibian species. Amphibians are dependent on riparian zones throughout their lives because of their class's unique life cycles and physical adaptations, including aquatic egg and larval stages and semi-terrestrial juvenile and adult stages (Walls et al, 1992). Most amphibian species have "stream-riparian associations," with many having life histories and adaptations that make them reliant on headwater landscapes (Olson et al, 2007).

Although wetlands are an important landform and provide vital ecological functions, approximately $30-50 \%$ of the world's wetlands have been degraded or are threatened due to anthropogenic stressors like forest clearing, wetland draining, urbanization and agriculture, as well as climate change stressors like rising temperatures and decreasing precipitation (Carvalho et al, 2020; Karraker \& Gibbs, 2009; Remm et al, 2018). Loss of wetlands and wetland degradation is a great cause for concern for amphibian populations, as this is a loss of vital habitat. This is one of the primary causes of amphibian declines around the world, with approximately $50 \%$ of amphibian species currently at-risk of decline because of loss or degradation of their habitat (Karraker \& Gibbs, 2009).

\section{Potential Impacts of Climate Change}

Wetlands are particularly vulnerable to climate change because it inevitably leads to reduced water inputs, which reduces groundwater recharge, severely altering water levels and hydroperiods (Hood \& Bayley, 2008; Popescu \& Gibbs, 2009). Many wetlands become degraded and dry out due to these stressors (Hood \& Bayley, 2008). This leads to a loss of wetland functions including groundwater recharge, nutrient removal, and wildlife habitat (Hood and Bayley, 2008). 
These climate variables are a serious concern for amphibians because, in times of drought, the altering of water levels and hydroperiods leads to amphibian die-offs because of increased chances of amphibian desiccation during all life stages (Popescu \& Gibbs, 2009). Many amphibians lay their eggs in ponds and, due to decreased stream water extent and shorter hydroperiods, these pools often dry before amphibian metamorphosis. This ecological trap greatly decreases the survival rate of larval amphibians, as well as adults that are moisturesensitive, and is a major factor that is leading to amphibian declines (Remm et al, 2018). Increased UV radiation exposure is also detrimental to amphibians due to their complex life cycles. UV radiation exposure, when combined with other anthropogenic environmental stressors, can cause a reduction of local species (Carvalho et al, 2020). Global climate change is another primary cause of amphibian declines, either through direct, indirect, or synergistic effects (Popescu \& Gibbs, 2009).

\section{Ecological Consequences of the Loss of Amphibians}

Amphibians are important components of their ecosystem food webs because of their diversity and ability to stabilize the food web (AmphibiaWeb, 2021; Dodd \& Cade, 1997). Being ectotherms, most of their energy is used for growth and reproduction rather than body temperature maintenance, making it possible for their populations to be relatively large (Dodd \& Cade, 1997). This allows their populations to influence community dynamics, serving as both high trophic level predators in their aquatic environments, as well as prey for other important species in forest environments (Walls et al, 1992). Also, due to their ability to transfer from the aquatic to the terrestrial ecosystems, they serve as a stable energy and matter flow between these systems (AmphibiaWeb, 2021). Without amphibians, the forest, wetland and aquatic food systems are out of balance.

\section{$\underline{B e a v e r}$ Conservation and Management in the Pacific Northwest}

Beavers (Castor canadensis and Castor fiber) were once abundant throughout the American and European ecoregions. However, during the fur trade of the 1800 s, they were hunted to extirpation throughout much of their historic range. The loss of beavers has had negative impacts on aspects of these forests, including forest energy cycling, ecological dynamics and landscape heterogeneity (Law et al, 2019).

Despite their extirpation, beavers have been able to make a recovery in North America and Europe. Beavers are classified as both ecosystem engineers and keystone species, showing that they have a great influence on the ecosystem and that there is great importance in supporting their populations. One vital part of the conservation of beavers and the management of their 
populations is reintroduction programs. Many of these programs are still ongoing in the United States, with many still in effect in the Pacific Northwest region (Pollock et al, 2018).

\section{Strategies and Findings of Beaver Reintroduction}

Reintroduction of biotic materials to positively influence ecosystem services through biotic and abiotic synergies is a common strategy for the conservation and restoration of degraded wetlands and their species. Focus is put on protecting forest landscapes through the management of animal populations to facilitate habitat restoration and species conservation. The reintroduction of beavers, or relocating beavers to ecosystems where they were once native in hopes that they will establish, is a practice that has been employed in the past by many ecological management organizations (Pollock et al, 2018). The main reasons for beaver reintroductions usually include restoration of landscape heterogeneity and increased flood and drought resilience (Law et al, 2019).

Studies have found that reintroducing beavers has positive impacts on the productivity and biodiversity of their surrounding ecosystem, terrestrial and aquatic (Hood et al, 2008; Hossack et al, 2015; Karraker et al, 2009; Law et al, 2019; Pollock et al, 2018; Popescu et al, 2009; Remm et al, 2018). Beavers are a keystone species due to the impact they have on an entire ecosystem; the effects they have on the ecosystem are disproportional with their abundance (Hossack et al, 2015). They are able to fundamentally alter local forest communities in positive ways, making their reintroduction a valuable alternative to wetland restoration via human manipulation (Hood and Bayley, 2008). Their reintroductions to ecoregions where they were once native have been found to have positive impacts on habitat conservation and ecosystem restoration (Polluck et al, 2018). As the creators of vital habitat, beavers could put ecosystems back into balance by performing important wetland and aquatic ecosystem processes. They could be a key to mitigating wetland drying and the disappearance of wetland species, as well as increasing wetland biodiversity, positively influencing wetland hydrology, increasing wetland hydroperiods, as well as many other wetland mitigation aspects.

\section{Ecological Effects of Beavers on Wetlands}

The beaver is a major influencer of wetland and riparian zone quality, productivity and biodiversity. Beavers are ecosystem engineers; they modify freshwater habitats through the building of their dams in order to raise and stabilize water levels to create a partly submerged structure which acts as their shelter. These structures are beneficial to the beaver because it provides protection from predators while also assisting in their foraging (Law at al, 2019). Through their structural manipulations of forest wetlands in order to build these structures, they influence major hydrologic processes of streams and riparian zones like the elevation of the 
water table, creation of new wetlands and extension of hydroperiods, (Law et al, 2019; Pollock et al, 2018; Hossack et al, 2015).

\section{Hydrology and Geomorphology}

Beaver dams have great influence over the physicochemical characteristics of streams and rivers, due to the structural manipulations of the landscape, including construction of burrows, canals, food caches, dams and the accumulation of woody debris (Rosell et al, 2005). They influence hydrologic processes of streams and riparian zones, creating ponds and modifying stream channel geomorphology and hydrology (Hood and Bayley, 2008).

Overbank flooding, caused by the pooling of water after the building of beaver dams, influences the hydrological processes of streams and rivers both spatially and temporally (Westbrook, 2006). The elevation of the water table upstream of their dams causes water to move laterally and downstream of the dams, greatly increasing the extent of water inundation. This creates more wetland area that is greater in depth and duration (Westbrook, 2006). Overbank flooding is also one of the main ways ground and soil water is replenished in wetlands, as it alters groundwater flows throughout valleys (Westbrook, 2006; Law, et al, 2019).

A series of beaver dams has the ability to change annual water discharge patterns, leading to increased flows during dry seasons due to increased water storage capacity. This could result in longer hydroperiods, with streams that were once intermittent flowing continuously (Rosell et al, 2005). Beavers create semi-permanent ponds as opposed to vernal (seasonal) ponds. Vernal ponds tend to be small and shallow, filling with water during the wet season and then drying up during warmer months of the year while beaver ponds persist on an annual basis and last for longer periods throughout the year (Karraker and Gibbs, 2009).

Beaver dams are also able to decrease stream regime and peak discharge rates, reducing flooding and erosion caused by run-off events (Rosell et al, 2005). The drainage network of rivers and streams can also be impacted by beaver dams. Westbrook found that a beaver dam created new surface water flow paths due to the dam steepening the groundwater flow gradient (2006). They concluded that the beaver's effect on hydrologic processes shows that beavers have a vital influence on the structure and function of wetlands and riparian zones.

\section{Landscape Heterogeneity}

Healthy beaver populations are able to maintain heterogeneity at a range of scales, from local to landscape (Law et al, 2019). At the landscape scale, heterogeneity is increased due to the landscape including patches of habitat that are beaver manipulated while other patches remain unaltered as well as newly formed and older or abandoned beaver dams coexisting (Law et al, 
2019). This creates diverse habitat, with a variety of wetlands that have different levels of hydroperiods (Karraker \& Gibbs, 2009). The mosaic of wetlands that usually form alongside beaver ponds also increases landscape heterogeneity, which shows that beavers have a large impact that extends beyond their disturbance (Popescu \& Gibbs, 2009; Cunningham et al, 2007). Beaver ponds are also unique systems when compared to other naturally forming ponds. They differ slightly in physical characteristics and tend to be more dynamic than other permanent wetlands. They have a fluctuating hydrological regime unlike other ponds that is caused by the constant changes to their dams. Beavers also continually disturb the habitat on smaller scales via herbivory and tree felling, accumulation of woody debris and continued channel engineering and canal excavation. All of these characteristics add to the heterogeneity of beaver engineered wetlands (Law et al, 2019).

\section{Biodiversity}

Through their manipulations of forest wetlands, beavers are able to increase riparian zone disturbance and plant and animal biodiversity (Law et al, 2019; Metts et al, 2001). One vital manipulation, over bank flooding, converts more terrestrial land into wetlands and plays a vital role in the nutrient and energy transfer between the aquatic and terrestrial ecosystems (Westbrook, 2006; Popescu \& Gibbs, 2009; Pollock et al, 2018). This influences the nutrient cycling of the forest ecosystem, as it facilitates exchange of sediment, water, and organic matter between rivers and streams and their riparian areas (Law et al, 2019). The beaver's ability to cause overbank flooding makes beavers a vital part of nutrient and energy transfer between the aquatic and terrestrial ecosystems, and influencers of the nutrient cycling of the forest ecosystem (Law et al, 2019). Due to the beaver dam's ability to raise the water table, the exchange of sediment, water, and organic matter between rivers and streams and their riparian areas is able to more readily take place (Law, et al, 2019). This helps to increase the productivity and quality of riparian habitats, which helps to increase biodiversity. Overbank flooding also increases the extent of wetland inundation, creating more wetland habitat for many species, including fish, water birds, mammals and herptiles, which also increases wetland biodiversity (Hood \& Bayley, 2008; Metts et al, 2001).

Multiple studies have shown that biodiversity has been enhanced in natural forest areas where beavers have been reintroduced. Law et al found that freshwater biodiversity is increased at the landscape scale through the reintroduction of beavers, with the species pools being larger in beaver ponds opposed to non-beaver ponds. The number of unique species in beaver ponds was $50 \%$ higher than unique species in other wetlands of the same region, showing that beaver ponds house a distinctive species assemblage. They found that beaver reintroduction and population management could be an important aspect of mitigating degraded landscapes and increasing freshwater biodiversity recovery (Law et al, 2019). 


\section{Ecological Effects of Beavers on Amphibians}

Many studies conclude that the restoration of the beaver could potentially be an important aspect of managing amphibian populations, including maintenance and recovery, as well as the restoration and management of rare amphibians (Dalbeck et al, 2007; Dalbeck et al, 2014; Elmeros et al, 2003; Hossack et al, 2015; Karraker \& Gibbs, 2009; Metts et al, 2001; Pollock et al, 2018; Popescu \& Gibbs, 2009). Some restoration efforts for amphibians include human made ponds that strive to replicate the small seasonal wetlands that are primary breeding habitats (Petranka \& Holbrook, 2006). Ecologists have tried to improve the design of these man-made ponds by incorporating information on natural history, community interactions, landscape ecology, and population dynamics (Petranka \& Holbrook, 2006). However, man made ponds are expensive, time consuming and don't always function as they should. Beaver created ponds are able to replace these man-made ponds in restoration efforts. The beaver's performance of vital ecosystem services through ecosystem engineering affects local abundance and dynamics of wetland wildlife, including amphibian populations (Pollock et al, 2018). Beaver presence has been found to increase amphibian habitability, amphibian breeding, population connectivity and climate change resilience. These findings show that the management of beavers translates to the management of amphibians (Popescu \& Gibbs, 2009).

\section{Amphibian Habitability}

Amphibian populations act as indicators for impacts of beavers on the landscape level because healthy amphibian populations are dependent on suitable wetland habitat (Dalbeck et al, 2014). Wetland ponds with higher habitat suitability tend to have higher population sizes of amphibians (Unglaub et al, 2018). Beaver ponds have been shown to make wetlands more habitable for amphibians, increasing their distributions (Hossack et al, 2015; Law, et al, 2019; Remm et al, 2018; Elmeros et al, 2003; Metts et al, 2001, Cunningham et al, 2006). Metts et al found beaver ponds to have a higher abundance of anurans (2001). Beaver ponds decrease stream regime, are lentic systems, and are oxygen-rich water bodies (vertical water mixing caused by constant inflows and outflows of water increases oxygen content), making them highly preferred habitat (Hossack et al, 2015, Karraker \& Gibbs, 2009, Popescu \& Gibbs, 2009).

Beavers also extend the hydroperiods of wetlands which is an important factor in the structuring of amphibian communities. Wetlands with longer hydroperiods, like those made possible by beavers, usually support more diverse amphibian populations (Cunningham et al, 2006). Babbit found that hydroperiod has the strongest influence on both amphibian species richness and the presence of amphibians in a habitat (2005). Beaver ponds diversify the range of the water bodies they influence and extend the amount of time amphibians can breed and grow (Karraker \& Gibbs, 2009; Remm et al, 2018). Dalbeck et al found that the increased habitat heterogeneity due to beaver occurrence led to an increased amphibian species richness in their study area (2007), 
while Cunningham et al came to similar conclusions, stating that beavers created wetland habitat with diverse hydroperiods and landscape heterogeneity that supports greater amphibian species richness (2006).

A study by Hossack at el found evidence of the positive influence of reintroduced beavers on wetlands, as well as amphibian populations (2015). They found evidence for the importance of beaver influence on amphibians with it being a parameter that described initial occupancy and colonization for the species studied. Their study was able to show effects of beavers fundamentally altering local communities of amphibians over several generations, showing that beavers had a persistent and lasting effect. They determined that the strong association between beavers and amphibians they saw shows that beavers benefit amphibian populations at local scales, possibly larger scales as well. Dalbeck et al found that amphibians prefer beaver ponds, with the number of species in beaver ponds being higher than in other water bodies in their study area (2007). Lehtinen \& Galatowitsch found that amphibians are able to rapidly colonize wetlands that have been restored and have the same characteristics of beaver ponds; many of the amphibian populations that were able to recolonize were able to successfully produce offspring within several months (2001).

\section{Amphibian Breeding}

Beaver ponds have been shown to be excellent diverse reproductive sites for amphibians, due to their spatial and temporal dynamics (Cunningham et al, 2007). Beaver dams change the physical characteristics of wetlands, making them a more preferred breeding habitat. The woody debris accumulation provides vital surfaces for the attachment of amphibian eggs (Dalbeck et al, 2007). The high inundation and insulation as well as shallow margins increases the water temperature of the wetland; the warmer water is able to speed the growth and development of ectothermic amphibian larvae (Hossack et al, 2015; Dalbeck et al, 2014). Amphibians prefer beaver ponds for breeding; Dalbeck et al found that beaver ponds contained almost all frog egg masses even though beaver ponds made up less than $50 \%$ of the lentic water bodies in their study area (2014).

Beaver ponds are able to support amphibian populations at all life stages, increasing amphibian fitness. Beaver floods produce nutrient rich sediments. These sediments are very important to many amphibian life cycles, as it favors periphyton, which is an important food source for tadpoles (Remm et al, 2018). Biofilm, another important food source for larvae, is also increased due to the woody debris that is present in beaver ponds, as it provides more surface area for the film to develop (Dalbeck et al, 2007). Beaver ponds also have a shallow littoral zone, which is a factor determining the occurrence of tadpoles in ponds (Remm et al, 2018). Beaver ponds are 
also larger than non-beaver ponds, making it possible for less competition among larvae. Karraker and Gibbs found this to increase survivability of amphibian juveniles, and increase their overall growth (2009). Due to their extended hydroperiods, beaver ponds are able to produce more adult frogs that have undergone metamorphosis (Karraker \& Gibbs, 2009, Pechmann et al, 1989). Pechmann et al found wetland hydroperiod to greatly affect amphibian community structure and dynamics due to its effect on size at and time of metamorphosis, which in turn affects amphibian adult fitness (1989).

The aquatic-terrestrial transfer of nutrients caused by overbank flooding not only increases the number of suitable spawning areas, but it also increases the quality of the habitat next to beavercreated pools (Elmeros et al, 2003). Microclimate, cover, and insect abundance are all positively influenced, improving the likelihood that amphibians entering the terrestrial environment following metamorphosis encounter habitats that are favorable (Karraker \& Gibbs, 2009). Also, because of the added nutrients, new metamorphs are speculated to stay near the beaver pond where they hatched, growing in size before dispersing into neighboring forests. This means that beaver ponds not only increase the survivability of juvenile amphibians, but also increase the survivability and fitness of adult amphibians, as their larger size will increase their chance of reaching reproductive age (Karraker \& Gibbs, 2009).

\section{Population Connectivity}

Due to the beaver's ability to increase the extent and duration of wetland inundation, they have the ability to facilitate population connectivity between amphibians in different wetland areas. In areas where valleys are unconfined and relatively flat, the hydrologic effects of beaver dams can extend far beyond the riparian areas adjacent to the river or stream (Westbrook, 2006). Beavers are able to influence hydrologic processes at large spatial scales, expanding, creating and maintaining wetlands and increasing wetland connectivity (Westbrook, 2006; Cunningham et al, 2007). The physical changes to wetland systems that result from the creation of beaver dams lead to larger wetlands that are inundated for longer periods throughout the year and that reach different wetland areas more often.

The spatial configuration of dams in a wetland with healthy beaver populations leads to beaver ponds occurring in chains along streams, with beaver ponds in a colony being closely connected, thereby reducing interwetland distance (Popescu \& Gibbs, 2009; Dalbeck et al, 2014;

Cunningham et al, 2007). Amphibians are limited in their dispersal abilities due to their physical characteristics; however, the average distance between beaver colonies is able to be crossed by 
amphibians relatively easily, which allows amphibian movements to disperse to another wetland area without the risk of desiccation (Dalbeck et al, 2014; Lehtinen et al, 2001). Beaver dams also create stream corridors, which provide conditions for movement that are favorable to most amphibians, including moist microclimates and plant cover (Cunningham et al, 2007). Wetlands with beaver influence have a higher permeability to amphibian movement and thus facilitate dispersal for breeding and foraging, which helps to stabilize populations of amphibians (Popescu \& Gibbs, 2009; Dalbeck et al, 2014; Cunningham et al, 2007).

The longer hydroperiods of beaver ponds, due to their persistence, maintain connectivity of wetland habitats and important connections between metapopulations of amphibians (Karraker \& Gibbs, 2009). Evidence that amphibians can disperse hundreds of meters to different wetland areas to breed shows that wetland connectivity is very important to their population dynamics (Olson et al, 2007). Longer hydroperiods that maintain wetland connectivity could play a large role in sustaining amphibian populations; Cunningham et al found that wetland connectivity was the best predictor for amphibian species richness and anuran breeding, concluding that conservation of pond-breeding amphibians is reliant on diverse hydroperiods and wetland connectivity (2007; Karraker \& Gibbs, 2009). This was also the finding of Babbit, who concluded that amphibian biodiversity can only be conserved if a diversity of hydroperiods in wetlands is maintained (2005).

\section{Climate Change Resilience}

Beavers are able to increase wetland and amphibian population resilience to climate change stressors including rising temperatures, droughts and less precipitation through their ability to create open water and wetlands at the landscape scale (Hood \& Bayley, 2008; Law et al, 2019). Even in times of severe temperature and precipitation fluctuations during a drought, beavers can significantly increase open water via overbank flooding and maintain wetlands (Popescu \& Gibbs, 2009; Hood and Bayley, 2008). They are able to increase surface and groundwater at times of high and low-flow and reduce the effect of decline in the water table in times of drought, meaning streams and riparian areas that have been altered by beavers are more resistant to disturbances (Hood \& Bayley, 2008).

The beaver's created semi-permanent wetlands are more likely to maintain amphibian populations during drought. These beaver-created wetlands could potentially re-colonize vernal pools that are more likely to dry out, which could help to preserve populations of amphibians during instances of climate stress (Karraker \& Gibbs, 2009). Their creation and maintenance of extensive wetlands with higher connectivity help amphibian populations be more resistant to climate change (Hossack et al, 2015; Westbrook et al, 2006). The threat of wetland draining due to climate stress makes it extremely important for the management of pools with longer hydroperiods that are also diverse in their range (Remm et al, 2018). 
Beavers as an Ecological Management Option for Amphibians in the Pacific Northwest

The goal of this work was to explore how beavers are linked with wetland hydrology, geomorphology, landscape heterogeneity, and biodiviersity and how these relate to amphibian species wetland habitability, breeding, population connectivity, and climate change resilience, in order to determine if beaver reintroduction and population management is a viable tool for the restoration of amphibian species of concern in the Pacific Northwest.

The Pacific Northwest is of special concern for this review for many reasons, including amphibian decline being particularly severe in this region, with population declines seen in multiple species, as well as the PNW being a major timber harvest region, which adds to increased disturbances and habitat loss to amphibian species (Walls et al, 1992). Many amphibians of the Pacific Northwest have specific ecological requirements; all 47 northwestern amphibian species have stream-riparian associations, with a third being reliant on general stream-riparian areas and a quarter being reliant on headwater landscapes due to their life histories (Olson et al, 2007).

This review focused on anuran species because beavers benefit this order of amphibians more due to their preferred habitat and special needs (Oregon Conservation Strategy). Beaver engineered habitats provide preferable habitat for species that require still or slow-moving water, as well as longer hydroperiods and warmer water for breeding, which mostly includes anuran species. Beavers are able to perform activities that substantially affect the terrestrial as well as aquatic habitats that are crucial for the specific requirements of many PNW anuran amphibians (Oregon Conservation Strategy). At-risk species of the Caudata order (salamanders) within the PNW would not benefit substantially from beaver reintroductions; beaver ecosystem engineering would not positively influence their vital habitat, talus slopes, and many salamanders require cold, flowing water for breeding (Oregon Conservation Strategy).

\section{Conservation of Pacific Northwest Amphibians}

Of the amphibian anuran species that are state or federally listed as sensitive, threatened, or endangered with large ranges throughout the PNW, including the Oregon Spotted frog, Cascades frog, Northern Red-legged frog, Foothill Yellow-Legged frog, Rocky Mountain Tailed frog, Columbia Spotted frog, Northern Leopard frog, and Coastal Tailed frog, all have special requirements that include still or slow moving water for breeding, as well as either permanent or longer lasting ponds (California Natural Resources Agency, 2021; Idaho Governor's Office of Species Conservation; Oregon Conservation Strategy; ODFW; WFWO; Wild research, 2015). Because of the beaver's ability to influence wetland habitat to be more habitable and better for breeding, as well as more connected and more resistant to climate change, beaver reintroductions 
into the ecoregions these at-risk species inhabitat would benefit their populations and help their conservation (Karraker \& Gibbs, 2009; Hood \& Bayley, 2008; Babbit, 2005; Cunningham et al, 2007; Dalbeck et al, 2007; Dalbeck et al, 2014; Hossack et al, 2015; Metts et al, 2001; Pollock et al, 2018; Popescu \& Gibbs, 2009; Rosell et al, 2005).

Table 1: State and federal listings for Pacific Northwest at-risk anuran species. For each species, its listing in each state and province within the PNW is shown, as well as its federal listing status.

\begin{tabular}{|c|c|c|c|c|c|c|}
\hline & Federal & Oregon & Washington & California & Idaho & $\begin{array}{l}\text { British } \\
\text { Columbia }\end{array}$ \\
\hline $\begin{array}{l}\text { Oregon Spotted } \\
\text { Frog }\end{array}$ & Threatened & -- & -- & -- & -- & -- \\
\hline Cascades Frog & -- & Sensitive & -- & Candidate & -- & -- \\
\hline $\begin{array}{l}\text { Northern Red- } \\
\text { legged Frog }\end{array}$ & -- & Sensitive & -- & $\begin{array}{l}\text { Special } \\
\text { Concern }\end{array}$ & -- & $\begin{array}{l}\text { Special } \\
\text { Concern }\end{array}$ \\
\hline $\begin{array}{l}\text { Foothill Yellow- } \\
\text { legged Frog }\end{array}$ & -- & Sensitive & -- & Endangered & -- & -- \\
\hline $\begin{array}{l}\text { Rocky Mountain } \\
\text { Tailed Frog }\end{array}$ & -- & Sensitive & Candidate & -- & -- & Endangered \\
\hline $\begin{array}{l}\text { Columbia Spotted } \\
\text { Frog }\end{array}$ & -- & Sensitive & Candidate & -- & Candidate & -- \\
\hline $\begin{array}{l}\text { Northern Leopard } \\
\text { Frog }\end{array}$ & -- & -- & Endangered & -- & -- & Endangered \\
\hline $\begin{array}{l}\text { Coastal Tailed } \\
\text { Frog }\end{array}$ & -- & Sensitive & -- & $\begin{array}{l}\text { Special } \\
\text { Concern }\end{array}$ & -- & $\begin{array}{l}\text { Special } \\
\text { Concern }\end{array}$ \\
\hline
\end{tabular}

For example, the Oregon Spotted frog requires permanent-semi-permanent ponds for breeding and depositing of eggs (Oregon Conservation Strategy). The conservation actions that have been proclaimed for this species includes improving habitat hydrology in order to extend hydroperiods for overwintering and provide larval habitat (Oregon Conservation Strategy). The most important aspect of their conservation includes maintaining healthy aquatic habitats (USFWS \& WFWO). Beaver reintroduction would therefore greatly benefit this species as reintroduction focuses on habitat restoration via beaver ecosystem engineering that influences wetland hydrology, quality and productivity (Hossack et al, 2015; Law et al, 2019; Pollock et al, 2018; Hood \& Bayley, 2008; Metts et al, 2001). Beaver dams also extend wetland hydroperiods, which would allow for this species to breed for longer, as well as increasing the amount of time habitat is available for larvae metamorphs (Babbit, 2005; Karraker et al, 2009; Pechman et al, 1989; Westbrook, 2006).

The Cascades frog also requires permanent-semi-permanent water sources. They need to have access to slow-moving water that is preferably shallow and sunny, since warmth speeds their 
larvae's development (Oregon Conservation Strategy). This species is vulnerable to genetic isolation so one of its main proclaimed conservation actions is maintaining habitat connectivity and increasing water quality within its range (Oregon Conservation Strategy). Beaver reintroduction would also greatly benefit this species as beavers provide slow moving, lentic systems that have been shown to be warm and of high enough quality for amphibian breeding and the speeding of metamorphosis (Westbrook, 2006; Hossack et al, 2015, Karraker \& Gibbs, 2009, Popescu \& Gibbs, 2009; Karraker and Gibbs, 2009). Beavers also have been shown to provide population connectivity to amphibians, due to their expansion of wetlands, which would highly benefit this species (Westbrook, 2006; Cunningham et al, 2007; Popescu \& Gibbs, 2009; Dalbeck et al, 2014; Karraker \& Gibbs, 2009).

A final example, the Northern Red-legged frog, is another species of PNW amphibian that prefers still-water habitat with exposed, sunny areas for breeding and depositing of eggs. This species' adults and juveniles also depend on moist riparian areas for emigration (Oregon Conservation Strategy). The proclaimed conservation measures for this species include maintaining connectivity between important sites and maintaining wetland and riparian habitat quality (Oregon Conservation Strategy). Beaver reintroduction would also benefit this species' conservation, as healthy beaver populations have been shown to maintain population connectivity between amphibians, as well as not only increase wetland habitat quality but also riparian area quality due to overbank flooding and nutrient transfer (Cunningham et al, 2007; Popescu \& Gibbs, 2009; Dalbeck et al, 2014; Karraker \& Gibbs, 2009, Westbrook, 2006; Law et al, 2019). Beavers also create exposed areas near their dams due to their herbivory and tree felling, which would provide this species with exposed, sunny areas for their breeding habits (Law et al, 2019).

The special needs and conservation actions are similar for all mentioned at-risk anuran species in the PNW (see table 1); beaver reintroductions would therefore benefit many at-risk amphibian species in this region (Oregon Conservation Strategy). Beaver reintroductions into the ecoregions within the PNW that the mentioned amphibians inhabit, which include the Coast Range, the Klamath Mountains, the West Cascades, the East Cascades, the Willamette Valley, the Blue Mountains, and the Northern Basin and Range should be a focus for conservation of these species (Oregon Conservation Strategy).

Conclusion

Through the meta analysis of different sources that ranged from beaver reintroduction studies to beaver presence studies as well as different amphibian species focuses, beaver reintroduction and beaver presence was found to be a valid form of ecological management for amphibian conservation in the PNW, particularly for the anuran order of amphibians. 
In the Pacific Northwest, beaver reintroduction and subsequent management of their populations could be a vital aspect of amphibian species conservation. Due to the many different positive influences that beavers have on amphibian populations, both directly and indirectly, the reintroduction of the beaver and the restoration and management of their populations in the Pacific Northwest is a vital part in the conservation of amphibian species and their wetland habitats. The linkage between beaver influence and amphibian habitability, breeding, population connectivity and climate change resilience was evidenced, showing that beavers greatly influence amphibian community structure and dynamics.

The management of riparian areas and wetlands is vital to any work that aims at conserving amphibian species. Because beavers have such a huge impact on these systems, it is of great importance that beaver reintroduction and population management be a primary component of ecological management and amphibian conservation in the Pacific Northwest.

\section{$\underline{\text { References }}$}

AmphibiaWeb. (2021, March 15). Amphibian Conservation: Why save amphibians? What is the scope of the problem, what are the causes, and what can be done? Retrieved July 30, 2020, from: https://amphibiaweb.org/declines/conservation.html

Babbit, K. J. (2005). The relative importance of wetland size and hydroperiod for amphibians in southern New Hampshire, USA. Wetlands Ecology and Management, 13, 269-279.

California Natural Resources Agency. (2021). State and Federally Listed Endangered and Threatened Animals of California. California Department of Fish and Wildlife. https://nrm.dfg.ca.gov/FileHandler.ashx?DocumentID=109405\&inline

Carvalho da Rocha, M., Beux dos Santos, M., Zanella, R., Prestes, O. D., Goncalves, A. S., $\&$ Schuch, A. P. (2020, September). Preserved riparian forest protects endangered forest-specialists amphibian species against the genotoxic impact of sunlight and agrochemicals. Biological Conservation, 249.

Cunningham, J. M., Calhoun, A. J., \& Glanz, W. E. (2007). Pond-Breeding Amphibian Species Richness and Habitat Selection in a Beaver-Modified Landscape. The Journal of Wildlife Management, 71(8), 2517-2526.

Dalbeck, L., Luscher, B., \& Ohlhoff, D. (2007). Beaver ponds as habitat of amphibian communities in a central European highland. Amphibia-Reptilia, 28, 493-501.

Dalbeck, L., Janssen, J., \& Volsgen, S. (2014). Beavers (Castor fiber) increase habitat 
availability, heterogeneity and connectivity for common frogs (Rana temporaria). Amphibia-Reptilia, 35, 321-329.

Dodd, K. C., \& Cade, B. S. (1997). Movement Patterns and the Conservation of Amphibians Breeding in Small, Temporary Wetlands. Conservation Biology, 12(2), 331-339.

Elmeros, M., Madsen, A., \& Berthelsen, J. (2003). Monitoring of reintroduced beavers (Castor fiber) in Denmark. Lutra, 46(2), 153-162.

Idaho Governor's Office of Species Conservation. (n.d.). Listed Species in Idaho. Retrieved July 30, 2021, from https://species.idaho.gov/listed-species-in-idaho/

Hood, G., \& Bayley, S. (2008). Beaver (Castor canadensis) mitigate the effects of climate on the area of open water in boreal wetlands in western Canada. Biological Conservation, 141(2), 556-567. doi:10.1016/j.biocon.2007.12.003

Hossack, B. R., Gould, W. R., Patla, D. A., Muths, E., Daley, R., \& Corn, P. S. (2015). Trends in Rocky Mountain amphibians and the role of beaver as a keystone species. Biological Conservation, 187, 260-269 doi: 10.1016/j.biocon.2015.05.005.

Karraker, N. E., \& Gibbs, J. P. (2009). Amphibian production in forested landscapes in relation to wetland hydroperiod: A case study of vernal pools and beaver ponds. Biological Conservation, 142, doi:10.1016/j.biocon.2009.05.002.

Law, A., Levanoni, O., Foster, G., Ecke, F., \& Willby, N. (2019). Are beavers a solution to the freshwater biodiversity crisis? Diversity and Distributions, 25(11), doi:10.1111/ddi.12978.

Lehtinen, R. M., \& Galatowitsch, S. M. (2001). Colonization of Restored Wetlands by Amphibians in Minnesota. The American Midland Naturalist, 145(2), 388-396.

Metts, B. S., Lanham, J. D., \& Russel, K. R. (2001). Evaluation of Herpetofaunal Communities on Upland Streams and Beaver-Impounded Streams in the Upper Piedmont of South Carolina. The American Midland Naturalist, 145(1), 54-65.

ODFW - Oregon Department of Fish and Wildlife. (2021). Sensitive Species List. U.S. Department of Fish and Wildlife. Retrieved July 30, 2021, from https://www.dfw.state.or.us/wildlife/diversity/species/docs/Sensitive_Species_List.pdf

Olson, D. H., Anderson, P. D., Frissell, C. A., Welsh, H. H., \& Bradford, D. F. (2007). Biodiversity management approaches for stream-riparian areas: Perspectives 
for Pacific Northwest headwater forests, microclimates, and amphibians. Forest Ecology and Management, 246(1), 81-107.

Oregon Conservation Strategy. (n.d.). Strategy Species, Amphibians. Retrieved July 30, 2021, from https://oregonconservationstrategy.org/ocs-strategy-species/amphibians/

Pechmann, J. H., Scott, D. E., Gibbons, W., \& Semlitsch, R. D. (1989). Influence of wetland hydroperiod on diversity and abundance of metamorphosing juvenile amphibians. Wetlands Ecology and Management, 1(1), 3-11.

Petranka, J. W., \& Holbrook, C. T. (2006). Wetland Restoration for Amphibians: Should Local Sites Be Designed to Support Metapopulations or Patchy Populations? Restoration Ecology, 14(3), 404-411.

Pollock, M.M., G.M. Lewallen, K. Woodruff, C.E. Jordan and J.M. Castro (Editors) 2018. The Beaver Restoration Guidebook: Working with Beaver to Restore Streams, Wetlands, and Floodplains. Version 2.01. United States Fish and Wildlife Service, Portland, Oregon. 189 pp. Online at: http://www.fws.gov/oregonfwo/ToolsForLandowners/RiverScience/Beaver.asp

Popescu, V., \& Gibbs, J. (2009). Interactions between climate, beaver activity, and pond occupancy by the cold-adapted mink frog in New York State, USA. Biological Conservation, 142(10), 2059-2068. doi:doi.org/10.1016/j.biocon.2009.04.001.

Remm, L., Vaikre, M., Rannap, R., \& Kohv, M. (2018). Amphibians in drained forest landscapes: Conservation opportunities for commercial forests and protected sites. Forest Ecology and Management, 428, 87-92. doi:10.1016/j.foreco.2018.06.038.

Rosell, F., Bozser, O., Collen, P., \& Parker, H. (2005). Ecological impact of beavers Castor fibre and Castor canadensis and their ability to modify ecosystems. Mammal Review, 35.

Unglaub, B., Steinfartz, S., Kuhne, D., Haas, A., \& Schmidt, B. R. (2018, March). The relationships between habitat suitability, population size and body condition in a pond-breeding amphibian. Basic and Applied Ecology, 27, 20-29.

USGS. Why are frogs and toad populations declining?

Retrieved April 16, 2020 from:

https://www.usgs.gov/faqs/why-are-frog-and-toad-populations-declining?qt-news_scienc e_products=0\#qt-news_science_products 
WFWO - Washington Fish and Wildlife Service. Oregon Spotted Frog. U.S. Fish and Wildlife Service. https://www.fws.gov/wafwo/articles.cfm?id=149489589

Walls, S. C., Blaustein, A. R., \& Beatty, J. J. (1992). Amphibian Biodiversity of the Pacific Northwest with Special Reference to Old-Growth Stands. The Northwest Environmental Journal, 8, 53-69.

Westbrook, C. J. (2006). Beaver dams and overbank floods influence groundwater-surface water interactions of a Rocky Mountain riparian area. Water Resources Research, 42(6), doi:10.1029/2005WR004560.

Wild Research. (2015). Amphibians in British Columbia that are Endangered, Threatened, or of Special Concern. Retrieved July 30, 2021, from: http://wildresearch.ca/wp-content/uploads/2015/10/2015-Oct-BC-Amphibian-List.pdf 